\title{
Vampires, Slashers, Or Zombies: Opening Weekend's Favorite Box Office Monster
}

Neil Terry, West Texas A\&M University, USA

Robert King, West Texas A\&M University, USA

Robin Patterson, West Texas A\&M University, USA

\begin{abstract}
This paper examines the determinants of opening weekend box office revenue of movies from the horror genre. The sample consists of 225 films released during 1978-2010. Regression results indicate the primary determinants of opening weekend box office revenue for horror movies are number of theatres showing the movie during the opening weekend of release, holiday release, critical rating, sequels, restricted rating, production budget, and theme. Specific results include the observation that within the horror movie genre, the vampire and slasher themes add approximately four to eleven million dollars to opening weekend box office revenue, while the comedic theme stalls at the box office with earnings totaling as much as four million dollars less than other movies in the genre. Nudity and the zombie theme are not statistically significant determinants.
\end{abstract}

Keywords: Critical Acclaim; Horror Movies; Movie Budget; Movie Revenue; Opening Weekend Box Office

\section{INTRODUCTION}

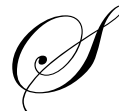

ince the first horror movie, Le Manoir Du Diable or The Haunted Castle, people have been drawn to a genre of film that is specifically designed to frighten and scare the viewer. Dracula is the second most portrayed character in film behind only Sherlock Holmes (Robertson, 2001). The 1897 publication of Bram Stoker's Dracula opened up the entire world's mind to the idea of vampires and their lifestyles, which increasingly came to creative life once depicted on the big screen. Building on the success of vampire films, horror began branching into other realms, such as monsters and ghosts. Frankenstein, Wolfman, and the Mummy became household names and staples in the early years of the motion picture industry. In 1932, the first zombie movie appeared with Dracula controlling the walking dead, opening the door for the popular idea of the zombie genre while staying in the comfort of the vampire umbrella of popularity. With Dracula being the conductor, the horror genre made quite a name for itself in the early days of film.

New forms of the horror genre have emerged into the spotlight within the last 40 years. The first true mainstream paranormal film was the Exorcist in 1973, which has become synonymous with the paranormal theme. From this popularity, other paranormal classics began emerging, such as Amityville Horror and Poltergeist, both of which had popular sequels and cult followings of their own. Also around this time, the first true crazed serial killers, or slasher movies, became popular with Friday the $13^{\text {th }}$, Texas Chainsaw Massacre, and Halloween releases. Their brilliant use of gore and horror ushered in a new level of fear previously missed by earlier genres. The slasher genre has continued the model of creating unique characters with box office demand by offering Freddy, Jason, and Mike Meyers as modern versions of Dracula and Frankenstein.

The horror movie genre continues to be an increasingly popular segment of the film market due to enjoyment of the unknown and the fondness for being taken out of our normal daily routine and immersed into a world of fear and imagination. The nature of horror movies has changed over the years, but the genre continues to find tremendous commercial success. Average production budgets for horror movies are under \$27 million while average profits are over $\$ 45$ million per film (Terry, King, Walker, 2010). The genre has also produced several profitable series of movies, including several with three or more movies in the series, including content derived from Nightmare on Elm Street, Friday the $13^{\text {th }}$, Halloween, Saw, Final Destination, Blade, Scream, and Twilight. 
Opening weekend is becoming increasingly important for the box office performance of all genres of films. This was not necessarily the case prior to the 1970's. Cucco (2009) claims that the film Jaws represents the turning point with its release in 1975. Jaws' promotion strategy was different than previous films and included a large concentration on television advertisements. This is considered to be the first time television was used en mass to promote a movie and the first time a movie was released in a record setting 464 theatres on the opening weekend (Cucco, 2009). That was the beginning of a strategy that is widely used now. Studios are increasingly using more and more of their promotion budget in the weeks before the film's release. Vogel (1998) finds that movies with successful opening weekends spend 80 percent of their advertising budget the week before the film's release in theatres. As a result, opening weekend box office performance of a movie is often a critical determinant of the overall financial success of a film.

A single movie can be the difference between millions of dollars of profits or losses for a studio in a given year (Simonoff \& Sparrow, 2000). The purpose of this research is to analyze the motion picture industry with a focus on the determinants of opening weekend domestic box office revenues for horror movies. This manuscript is divided into four sections. First, a survey of the literature related to financial performance of movies is discussed. The second section provides the model specification. The third section puts forth an empirical evaluation of the determinants of opening weekend box office revenues for 225 horror movies released during the years 1978-2010. The final section offers concluding remarks.

\section{SURVEY OF THE LITERATURE}

Although no research has focused exclusively on opening weekend box office performance of the horror movie genre, many researchers have developed models that explore the potential determinants of motion picture box office performance and related issues. Litman (1983) was the first to develop a multiple regression model in an attempt to predict the financial success of films. The original independent variables in the landmark work include movie genre (science fiction, drama, action-adventure, comedy, and musical), Motion Picture Association of America rating (G, PG, R and $\mathrm{X}$ ), superstar in the cast, production costs, release company (major or independent), Academy Awards (nominations and winning in a major category), and release date (Christmas, Memorial Day, summer). Litman's model provides evidence that the independent variables of production costs, critics' ratings, science fiction genre, major distributor, Christmas release, Academy Award nomination, and winning an Academy Award are all significant determinants of the success of a theatrical movie. Litman and Kohl (1989), Litman and Ahn (1998), and Terry, Butler, and De'Armond (2004) have replicated and expanded the initial work of Litman. None of the extensions of Litman's work has explicitly focused on the determinants of opening weekend box office revenue of the horror movie genre.

Opening weekend box office performance of a movie is often a critical determinant of the overall financial success of a film. In the case of motion pictures, decay effects means the diminishing attractiveness of movies as time goes on. The sales pattern of widely released movies shows an exponential distribution where the early period sales are the highest and drop throughout the life cycle (Liu, 2006). Therefore, the box office revenue at some later week is usually less than that of previous weeks. According to Einav (2007) in his reduced form of individual utility, there could be two possible effects that are captured by the decay effect: First, potential markets shrink over time because most people go to a movie only once. Second, watching a movie earlier is preferred by consumers. The result of the study shows the estimated decay of revenues of almost 40 percent per week. In addition, the selling price in secondary distribution channels such as home video sales and rentals depend greatly on the boxoffice performance in the first weeks of box office release. The larger the success of the first night, the higher the price in secondary markets (Cucco, 2009). The life-cycle of films has been shortened by the importance and large distribution during opening weekend releases.

One strong area of interest in the movies literature has been the role of the critic (Weiman, 1991). The majority of studies find that critics play a significant role on the success or failure of a film. Eliashberg and Shugan (1997) divide the critic into two roles, the influencer and the predictor. The influencer is a role where the critic will influence the box office results of a movie based on his or her review of the movie. Eliashberg and Shugan's results suggest that critics have the ability to manipulate box office revenues based on their review of a movie. The predictor is a role where the critic, based on the review, predicts the success of a movie but the review will not 
necessarily have an impact on how well the movie performs at the box office. Eliashberg and Shugan show that the predictor role is possible but does not have the same level of statistical evidence as the influencer role.

King (2007) explores the theoretical power and weakness of critics on the box office performance of movies. The substantial market power of critics is derived from the following: (1) Film reviews are widely available in newspapers, magazines, and websites. The ubiquitous availability of critical reviews in advance of a movie release creates positive or negative energy in the critical opening weeks; (2) Film critics regard themselves as advisors to their readers. They are often as explicit in their recommendations as Consumer Reports is about other consumer purchases; and (3) Film critics are likely to be considered objective. There are too many critics and too many films for serious critical bias to develop. Those who are skeptical about the influence of film critics point to the following counter arguments: (1) It is possible that the effects of aggressive marketing at the time of a film's release might dominate critical evaluations in determining opening attendance; (2) Critics may raise issues that do not concern most audiences. They are more likely to notice and comment on technical issues, like cinematographic technique, than the average member of the audience; and (3) Critics may write for a readership that has different tastes from the average cinemagoer. The most obvious potential reason for this is demographic. Cinema audiences are younger than the general population and less likely to pay attention to print reviews. Critics might therefore, be expected to aim their reviews at the older demographic audience and give relatively negative reviews to certain film genres. The empirical results put forth by King (2007) are mixed with respect to the impact of critics on box office earnings for the U.S. box office in 2003. He finds zero correlation between critical ratings for films and gross box office earnings when all releases are considered because of the affinity critics have for foreign movies and documentaries relative to the general public. For movies released on more than 1,000 screens, critical ratings have a positive impact on gross earnings.

Reinstein and Snyder (2000) focus on the critics Siskel and Ebert and how their reviews impact box office success. The authors report that the correlation between good movie reviews and high demand might be false due to unknown quality measurements. In order to circumvent the proposed false correlation Reinstein and Snyder apply a "differences in differences" approach that yields a conclusion that positive reviews have a surprisingly large and positive impact on box office revenue. Reinstein and Snyder also report that their results show that the power to influence consumer demand does not necessarily lie in the entire critic population, but may lie in the hands of a few critics.

Wallace, Seigerman, and Holbrook (1993) employ a sample of 1,687 movies released from 1956 through 1988 to investigate the relationships between movies box office success and critic ratings. They find a poorly rated movie will actually lose money for every positive review it receives while a highly rated movie will continue to gain money for every positive review it receives. Wallace, Seigerman, and Holbrook (1993, p. 11) interpret these findings by saying that "it appears that a bad movie has something to gain by being as trashy as possible. ... [For] a good movie, it apparently pays to strive for even greater excellence." Ravid (1999) has also looked at movie reviews as a source of projecting higher revenues. He concludes that the more reviews a film receives, positive or negative, the higher revenues it will obtain.

Although much research has supported the critic as a positive indicator of box office success, others have shown that the critic plays a much less important role. Levene (1992) surveyed students at the University of Pennsylvania and concludes from her 208 useable surveys that positive critic reviews ranked tenth, behind plot, subject, and word-of-mouth on a list of factors that influence the decision to watch a film. Levene's study reveals that theatre trailers and television advertising were the two most important determinants. Faber and O'Guinn (1984) conclude that film advertising, word-of-mouth and critics' reviews are not important compared to the effect that movie previews and movie excerpts have on the movie going public. Wyatt and Badger (1984) find that negative or positive reviews have little effect on the interest of an individual to see a movie over a mixed review or seeing no review. Further research by Wyatt and Badger (1987) conclude that positive reviews and reviews that contain no evaluative adjectives, which they called non-reviews, are deemed more interesting than a review that was negative or mixed. More recently, Wyatt and Badger (1990) report that reviews containing high information content about a movie raise more interest in a film than a positive review. 
Research has shown a seasonal pattern in movie releases and box office performance. Litman (1983) reports that the most important time for a movie release is during the Christmas season. Sochay (1994) counters this with evidence that the summer months are the optimal time of year to release a motion picture. Sochay, referencing Litman (1983), explains his conflicting results are due to competition during the peak times. Sochay adds that the successful season will shift from the summer to Christmas in different years due to film distributors avoiding strong competition. Radas and Shugan (1998) developed a model that captures the seasonality of the motion picture industry and apply it to the release of thirty-one movies. The authors find that the length of a movie release on average is not longer during the peak season but peak season movies typically perform better at the box office. Einav (2001) investigates seasonality in underlying demand for movies and seasonal variation in the quality of movies. He finds that peak periods are in the summer months and the Christmas season because distributors think that is when the public wants to see movies and when the best movies are released. He comments that distributors could make more money by releasing "higher quality" movies during non-peak times because the movie quality will build the audience and there will be less competition than at peak times.

Film ratings passed down from the Motion Picture Association of America (MPAA) may also influence box office performance. Many film companies fight for a better rating, often re-shooting or re-editing scenes multiple times in order to get their preferred ratings, most often being PG or PG-13 because these ratings exclude virtually no one from seeing the movie. Sawhney and Eliashberg (1996) develop a model where the customer's decision-making process on whether to see a movie can be broken into a two-step approach, time-to-decide and time-to-act. The results of their study show that movies with an MPAA rating of restricted (rated R) perform worse at the box office than movies without a restricted rating. The analysis shows that restricted rated movies have a higher time-to-act but have longer time-to-decide periods than family movies. Terry, Butler, and De'Armond (2004) verify the negative impact of the restricted rating on box office performance, providing evidence of a penalty in excess of \$10 million. Ravid (1999) provides evidence from a linear regression model that G and PG rated films have a positive impact on the financial success of a film. Litman (1983), on the other hand, finds that film ratings are not a significant predictor of financial success. Austin (1984) looks at film ratings in an attempt to find a correlation between ratings and movie attendance but find no significant relationship.

Anast (1967) was the first to look at how film genre relates to movie attendance. His results show that action-adventure films produce a negative correlation with film attendance while films containing violence and eroticism had a positive correlation. Litman (1983) shows that the only significant movie genre is science fiction. Sawnhey and Eliashberg (1996) use their two-step approach and find that the drama genre has a slower time-to-act parameter while action movies result in a faster time-to-decide than other movie genres. Neelamegham and Chinatagunta (1999) employ a Bayesian model to predict movie attendance domestically and internationally. They conclude the thriller and action themes are the most popular in the worldwide market, while romance genre was the least popular.

Awards are important to every industry but few industries experience financial compensation from an award more than the motion picture industry (Lee, 2009). Litman (1983) shows that an Academy Award nomination in the categories of best actor, best actress, and best picture is worth $\$ 7.34$ million, while winning a major category Academy Award is worth over \$16 million to a motion picture. Smith and Smith (1986) point out that the power of the Academy Award explanatory variable in models explaining patterns in movie rentals will change over time as the effects of different Academy Awards could cause both positive and negative financial results to a movie in different time periods. Nelson, Donihue, Waldman, and Wheaton (2001) estimate that an Academy Award nomination in a major category could add as much as $\$ 4.8$ million to box office revenue, while a victory can add up to $\$ 12$ million. The authors find strong evidence toward the industry practice of delaying film releases until late in the year as it improves the chances of receiving nominations and monetary rewards. Dodds and Holbrook (1988) look at the impact of an Academy Award after the nominations have been announced and after the award ceremony. The authors find that a nomination for best actor is worth about $\$ 6.5$ million, best actress is worth $\$ 7$ million and best picture is worth $\$ 7.9$ million. After the award ceremony the best actor award is worth $\$ 8.3$ million, best picture is worth $\$ 27$ million, and best actress award is not statistically significant. Simonoff and Sparrow (2000) find that for a movie opening on less than ten screens, an Academy Award nomination will increase the movies expected gross close to 250 percent more than it would have grossed if it had not received the nomination. For movies opening on more than ten screens, an Academy Award nomination will increase the movies 
gross by nearly 30 percent.

Literature investigating movie revenue streams beyond the box office are limited. Chiou (2008) explores the timing of a theatrical release as it relates to the home video industry and finds the highest demand season for the video market is between Thanksgiving and Christmas. Terry and De'Armond (2008) employ regression analysis to investigate the determinants of movie video rental revenue. They find domestic box office, Academy Award nominations, and domestic release exposure to be positive and significant determinants of movie video rental revenue. Time to video, sequels, and children's movies are shown to have a negative and statistically significant impact on video rental revenue.

\section{DATA AND MODEL}

Predicting the financial performance of feature films is widely regarded as a difficult endeavor. Each film has a dual nature, in that it is both an artistic statement and a commercial product (Sochay, 1994). Many studies have attempted to estimate the determinants of box office performance by employing empirical models to high profile features. The approach of this study provides a unique focus on the determinants of opening weekend box office revenue for horror movies. The sample includes a total of 225 motion pictures released during 1978-2010 that are classified by boxofficemojo.com as horror movies.

The primary source of data for this study is the Rotten Tomatoes website (rottentomatoes.com). The website utilizes a unique rating system that summarizes positive or negative reviews of accredited film critics into an easy to use total percentage that is aggregated for each motion picture. In addition to providing a system of aggregate reviews, the website also contains information pertaining to revenue, release date, movie rating, and genre. Movies.com, Oscars.org, WorldwideBoxoffice.com, boxofficemojo.com, imdb.com, and the-numbers.com are additional sources of data and information. specified as:

The empirical model employed to investigate the determinants of box office performance for this study is

(1) OBOXOFFICE $_{\mathrm{i}}=\mathrm{B}_{0}+\mathrm{B}_{1}$ THEATRES $_{\mathrm{i}}+\mathrm{B}_{2}$ HOLIDAY $_{\mathrm{i}}+\mathrm{B}_{3}$ CRITIC $_{\mathrm{i}}+\mathrm{B}_{4}$ SEQUEL $_{\mathrm{i}}+\mathrm{B}_{5}$ COMEDY $_{\mathrm{i}}+$ $\mathrm{B}_{6}$ SLASHER $_{\mathrm{i}}+\mathrm{B}_{7}$ VAMPIRE $_{\mathrm{i}}+\mathrm{B}_{8}$ ZOMBIE $_{\mathrm{i}}+\mathrm{B}_{9}$ RESTRICTED $_{\mathrm{i}}+\mathrm{B}_{10}$ NUDITY $_{\mathrm{i}}+\mathrm{B}_{11}$ BUDGET $_{\mathrm{i}}+\mathrm{u}_{\mathrm{i}}$

where OBOXOFFICE is opening weekend domestic box office earnings adjusted for inflation and presented in real 2010 dollars, THEATRES is number of theaters featuring the movie during opening weekend, HOLIDAY is a categorical variable for movies released the weekend on/or before Halloween or on a Friday the $13^{\text {th }}$, CRITIC is the percent of composite approval rating for a movie by a group of leading film critics, SEQUEL is a categorical variable for movies that are derived from a previously released film, COMEDY is a categorical variable for horror movies classified as spoofs or comedic theme, SLASHER is a categorical variable for horror movies with a slasher theme, VAMPIRE is a categorical variable for horror movies with a vampire theme, ZOMBIE is a categorical variable for horror movies with a zombie theme, RESTRICTED is a categorical variable for movies with a restricted rating (Rated R), NUDITY is a categorical variable for movies tagged with female frontal nudity, and BUDGET controls for the estimated production and promotion costs for each movie after being adjusted for inflation by converting all nominal values to 2010 real values. Several alternative model specifications were considered including control variables for independent films, presence of an established star actor or director, Academy Award nominations, and new release competition. Inclusion of these variables into the model created problems with multicollinearity concerns with other variables included in the model or did not significantly improve model explanatory power. For these reasons, they are not included in the final model.

Descriptive statistics for the model variables are presented in Table 1. The average opening weekend box office revenue in the sample is $\$ 14.6$ million, with a maximum of $\$ 146.2$ million (Twilight: New Moon). The six films in the research cohort with an opening weekend box office performance greater than $\$ 50$ million are Twilight: New Moon (\$146.2 million), Halloween (\$85.7 million), Twilight (\$71.3 million), Twilight: Eclipse (\$64.8 million), Van Helsing (\$60.4 million), and An Interview with a Vampire (\$53.8 million). Number of theaters showing a film during the opening weekend is expected to have a positive impact on domestic box office. Twilight: Eclipse is the 
cohort leader for opening number of theatres at 4,468 followed closely by Twilight: New Moon (4,024 opening theatres) and Van Helsing (3,500 opening theaters). Holiday releases are expected to have a positive impact on the box office revenue of horror movies, with 12 percent of the films in the research sample classified as holiday releases. The holiday variable is expected to have a positive impact on opening weekend box office revenue for horror movies as a holiday like Halloween would appear to be a natural time for consumers to prioritize watching a horror movie. Average critical rating of the movies in the research cohort is approximately 37.8 percent positive with a standard deviation of 26.5. Evil Dead 2 ( $\$ 1.6$ million in opening weekend box office revenue) is the most positively reviewed movie in the sample at 98 percent critically approved, while One Missed Call $(\$ 12.8$ million in opening weekend box office revenue) is the lowest critically reviewed movie with no positive reviews. The expectation is for critical acclaim to have a positive correlation with opening weekend box office success. Horror movies with a comedy theme characterize 14 percent of the research sample, 36 percent have a slasher theme, 19 percent have a vampire theme, 15 percent have a zombie theme, 77 percent of the movies in the sample have a restricted rating, and 33 percent are sequels. The box office success of Twilight series combined with the historical success of the Dracula character provides reason to believe the vampire theme is the most successful, although the anticipated sign on coefficients associated with comedy, slasher, or zombie themes is uncertain. Rated R movies are expected to have a negative impact on opening weekend box office revenue because the rating restricts attendance to individuals 17 years of age and older. Sequels should have a positive impact on opening weekend box office revenue based on the assumption sequels have a loyal sector of fans following the continuation of the story line. Thirty percent of the movies in the sample have scenes with explicit nudity. Many horror movies follow a formula of graphic violence combined with nudity in an effort to attract young male viewers. The budget for movies in the research sample varies from a low of $\$ 15,355$ (Paranormal Activity) to a high of $\$ 198.4$ million (Van Helsing). Movies with a large budget are expected to find greater opening weekend box office success.

Table 1: Summary Statistics for Horror Movies (1978-2010)

\begin{tabular}{lcccc}
\hline Variable & Mean & Maximum & Minimum & Standard Dev. \\
\hline OBOXOFFICE & $14,587,712$ & $146,223,951$ & 8,199 & $15,838,879$ \\
THEATRES & 1,732 & 4468 & 5 & 1,039 \\
HOLIDAY & 0.12 & 1 & 0 & 0.327 \\
CRITIC & 37.82 & 98 & 0 & 26.46 \\
SEQUEL & 0.33 & 1 & 0 & 0.473 \\
COMEDY & 0.14 & 1 & 0 & 0.351 \\
SLASHER & 0.36 & 1 & 0 & 0.480 \\
VAMPIRE & 0.19 & 1 & 0 & 0.394 \\
ZOMBIE & 0.15 & 1 & 0 & 0.360 \\
RESTRICTED & 0.77 & 1 & 0 & 0.425 \\
NUDITY & 0.30 & $198,486,487$ & 0 & 0.457 \\
BUDGET & $26,266,025$ & & 15,355 & $25,781,175$ \\
\hline
\end{tabular}

$\mathrm{n}=225$

\section{DETERMINANTS OF BOX OFFICE REVENUE OF HORROR MOVIES}

The estimated empirical relationship between the explanatory variables and opening weekend box office revenue for horror movies is presented in Table 2. Two model specifications are put forth based on incomplete data for the BUDGET variable. The first is the full model, which includes all 225 movies in the sample. The second specification only includes the 144 movies that have BUDGET information available. The full and reduced model specifications are extremely consistent. Both models explain over 50 percent of the variance in horror movie opening weekend box office revenue. None of the independent variables have a correlation higher than 0.48 (THEATRES and BUDGET have the highest correlation), suggesting that excessive multicollinearity is not a problem with the analysis. Nine out of the eleven independent variables are statistically significant in at least one model specification.

The first variable in the model is number of theatres showing the movie during the opening weekend (THEATRES). The empirical results indicate that number of theatres has a positive and statistically significant impact on opening weekend box office revenue for horror movies. The results imply that successful horror movies 
need the studio support of pushing for a wide release. The two regression models imply an increase of approximately $\$ 10$ million in opening weekend domestic box office revenue for every extra 1,000 theatres showing a movie during the critical opening weekend. The results are not surprising given the box office success of most of the high profile wide release movies, which include Twilight: Eclipse (4,468 opening weekend theatres with opening weekend box office earnings of $\$ 64.8$ million), Twilight: New Moon (4,024 opening weekend theatres with opening weekend box office earnings of $\$ 146.2$ million), Van Helsing (3,500 opening weekend theatres with opening weekend box office earnings of $\$ 60.4$ million), Scream 3 (3,467 opening weekend theatres with opening weekend box office revenue of $\$ 44.4$ million), and Twilight (3,419 opening weekend theatres with opening weekend box office earnings of $\$ 71.3$ million). The only movies with a wide release of over 3,000 theatres that significantly underwhelmed at the opening weekend box office are House of Wax (3,111 opening weekend theatres with opening weekend box office earnings of $\$ 13.7$ million), Blair Witch 2 (3,317 opening weekend theatres with opening weekend box office earnings of $\$ 13.2$ million) and Vampires Suck (3,233 opening weekend theatres with opening weekend box office earnings of $\$ 12.2$ million).

Table 2: Determinants of Opening Weekend Box Office Revenue (1978-2010)

\begin{tabular}{|c|c|c|c|c|}
\hline \multirow[t]{2}{*}{ Variable } & \multicolumn{2}{|c|}{$\begin{array}{c}\text { Full-Model Coefficient } \\
\text { (t-statistic) }\end{array}$} & \multicolumn{2}{|c|}{$\begin{array}{c}\text { Reduced Model Coefficient } \\
\text { (t-statistic) }\end{array}$} \\
\hline & $-7,552,382$ & $\left(-2.65^{*}\right)$ & $-14,590,328$ & $(-3.07 *)$ \\
\hline THEATRES & 9,691 & $\left(11.49^{*}\right)$ & 10,641 & $(6.88 *)$ \\
\hline HOLIDAY & $3,928.096$ & $(1.68 * *)$ & $7,200,128$ & $(2.44 *)$ \\
\hline CRITIC & 146,520 & $(4.63 *)$ & 201,592 & $(4.74 *)$ \\
\hline SEQUEL & $4,007,490$ & $(2.22 *)$ & $3,595,313$ & $(1.97 *)$ \\
\hline COMEDY & $-3,725,759$ & $\left(-1.65^{* *}\right)$ & $-3,785,810$ & $(-1.21)$ \\
\hline SLASHER & $4,362,209$ & $(1.99 *)$ & $9,174,130$ & $(2.84 *)$ \\
\hline VAMPIRE & $6,985,179$ & $(2.93 *)$ & $11,337,097$ & $(3.18 *)$ \\
\hline ZOMBIE & $1,635,891$ & $(0.58)$ & $3,634,528$ & (1.13) \\
\hline RESTRICTED & $-6,113,342$ & $\left(-2.70^{*}\right)$ & $-9,945,831$ & $(-3.20 *)$ \\
\hline NUDITY & 357,298 & $(0.19)$ & $1,550,818$ & $(0.59)$ \\
\hline BUDGET & & & 0.1308 & $\left(2.54^{*}\right)$ \\
\hline $\mathrm{N}$ & \multicolumn{2}{|c|}{225} & \multicolumn{2}{|c|}{144} \\
\hline R-square & \multicolumn{2}{|c|}{0.5020} & \multicolumn{2}{|c|}{0.5309} \\
\hline F-Value & \multicolumn{2}{|c|}{$15.07 *$} & \multicolumn{2}{|c|}{$16.68^{*}$} \\
\hline
\end{tabular}

Notes: $* \mathrm{p}<.05$, and $* * \mathrm{p}<.10$.

The release of a horror movie during a holiday weekend is positive and statistically significant in both model specifications. The HOLIDAY variable captures horror movies released on Halloween or Friday the $13^{\text {th }}$ weekends. The Holiday variable is positive with a coefficient ranging from approximately $\$ 4$ million to $\$ 7$ million in the two models. Several movies in the Friday the $13^{\text {th }}$, Nightmare on Elm Street, and Halloween series tend to be holiday releases that are solid box office performers.

The variable CRITIC is the percent approval rating for a film by a leading group of movie reviewers. Conventional wisdom suggests that critical reviews are extremely important to the popularity of movies, especially in the early stages of a release. Good reviews are expected to stir curiosity and identify quality, while poor reviews are expected to limit the interest of the influential early adopters. More practically speaking, the advertising agency will select favorable excerpts from reviews and incorporate them in its media campaign to give the impression of critical acclaim (Litman, 1983). Empirical evidence supports the positive and significant impact critics have on the box office as a box office predictor or influencer (Litman \& Kohl, 1989; Eliashberg \& Shugan, 1997; Reinstein \& Snyder, 2000; Terry, Butler \& De'Armond, 2004; and King, 2007). Not surprisingly, the CRITIC variable is positive and statistically significant in both model specifications. Critical acclaim for movies in the horror genre is rare, which is supported by the observation that only 37.82 percent of the reviews for the movies in the research sample are positive. The regression coefficients imply a ten percent increase in critical approval raises opening weekend box office earnings by $\$ 1.4$ million to $\$ 2$ million. The few movies that receive positive critical reviews have an advantage at the box office. Scream 2 ( 80 percent positive reviews with opening weekend box office of 
$\$ 44.7$ million), Bram Stroker's Dracula (82 percent positive reviews with opening weekend box office of $\$ 47.8$ million), Poltergeist (86 percent positive reviews with opening weekend box office of $\$ 15.8$ million), and Halloween (93 percent positive reviews with opening weekend box office of $\$ 85.7$ million) are examples of horror movies with positive critical reviews and strong box office earnings. There are numerous movies with critical reviews that are less than 10 percent and none of the poorly reviewed movies have real opening weekend domestic box office earnings greater than $\$ 10$ million. The list of movies with low critical ratings and limited opening weekend box office success includes The Horror Show (1 percent positive reviews with opening weekend box office of $\$ 1.4$ million), The Haunting of Molly Hartley ( 3 percent positive reviews with opening weekend box office of $\$ 5.6$ million), House of the Dead (4 percent positive reviews with opening weekend box office of $\$ 6.7$ million), Soul Survivors (4 percent positive reviews with opening weekend box office of $\$ 1.4$ million), The Forsaken (8 percent positive reviews with opening weekend box office of $\$ 3.7$ million), and Dracula: Dead and Loving It (9 percent positive reviews with opening weekend box office of \$3.9 million). Academy Awards are an explicit form of critical acclaim that is often considered in empirical research on the financial performance of movies. Award consideration is not included in this model because of the very low propensity for movies from the horror genre to receive Academy Award nominations.

The movie sequel has been around for many years but it can be argued that no genre is more dependent on the sequel than the horror movie genre. A total of 75 sequels are offered in the sample, which is one-third of the total sample cohort. Sequels are produced to capture an existing audience associated with the success of a previously popular film. There are no guarantees in the motion picture industry but the positive relationship between moviegoers and a specific storyline and characters is extremely close. The SEQUEL variable is defined in this study as a movie derived from previous released material (e.g., sequel, prequel, or remake). The results indicate the variable is a positive and statistically significant determinant of opening weekend box office revenue for horror movies. The SEQUEL coefficient ranges between $\$ 3.5$ million and $\$ 4$ million. The Twilight sequels are the most successful in the sample but Scream, Saw, Halloween, Friday the $13^{\text {th }}$, and Blade all have at least three installments in a series of movies with opening weekend box office earnings always well in excess of the $\$ 14.58$ million research sample average.

One commonly used, yet rarely found to be significant contributor to box office success is the content category (Litman, 1983; Litman \& Kohl, 1989; Sochay, 1994). Four variables are used to control for type of horror movie content in this study. They are COMEDY, SLASHER, VAMPIRE, and ZOMBIE. Three of the four content variables are statistically significant in at least one model specification. The results reveal the categorical variables controlling for horror movies with a comedic theme is negative and statistically significant in one of the model specifications. The results imply fans of horror movies generally do not like to mix the genre with a comedic spin. Zombieland (opening weekend box office revenue of $\$ 25.3$ million) is one of the only comedy theme horror movies in the sample with modest box office success as most movies in the category perform closer to the cult classic Shaun of the Dead (opening weekend box office revenue of $\$ 3.9$ million). The VAMPIRE variable is positive and statistically significant with a coefficient ranging between $\$ 7$ million and $\$ 11$ million. The statistically significant coefficient for the VAMPIRE variable is not surprising given four of the top domestic box office movies in the sample (the three Twilight movies and Interview with a Vampire) are vampire thematic. Vampires are still popular with the incredibly cult-like following of the Stephenie Meyer Twilight series, which reaches out to a new generation with the vampire theme. Slasher movies dominate the horror movie genre with 81 of the 225 movies in the research sample falling into the slasher theme. Not surprisingly, the slasher theme is statistically significant in both model specifications with a positive opening weekend revenue coefficient ranging from $\$ 4$ million to $\$ 9$ million. Freddy in the Nighmare on Elm Street movies, Mike Myers in the Halloween movies, Jason in the Friday the $13^{\text {th }}$ movies, and Jigsaw in the Saw movies are a few of the legendary slasher characters in the horror movie genre. With few exceptions, horror movies do not usually employ award winning or A-list actors, actresses, or directors. The true stars in the horror movie genre are familiar characters like Jason and Jigsaw. The ZOMBIE variable is revealed to be positive but statistically insignificant. The zombie theme represents 15 percent of the research sample but Resident Evil: Apocalypse (opening weekend box office earnings of \$26.9 million) is the only zombie thematic movie to earn more than $\$ 26$ million in the opening weekend while ten zombie thematic movies have opening weekend earnings below $\$ 3$ million. 
Another element that can affect the financial performance of a film is the rating assigned by the Motion Picture Association of America. The motion picture industry established the code as a means of giving advance information to parents and others about the theme and treatment of films. This voluntary code was adopted to prevent stringent forms of governmental controls. There are four possible ratings given to films in the research sample - G (general audiences), PG (parental guidance suggested), PG-13 (possibly unsuitable for children less than 13 years of age), and R (restricted; children not admitted unless accompanied by an adult). The conventional wisdom is that the family product sells, while an adult theme or treatment has a limited customer base because of age restrictions limiting access to the lucrative teenage market. This hypothesis is verified by the negative and statistically significant coefficient associated with the RESTRICTED variable in both model specifications. The penalty in opening weekend box office loss associated with restricted movies is very large, ranging from $\$ 6$ million to $\$ 10$ million in the two linear model specifications. The results confirm the decision of many motion picture companies to push the envelope at the PG-13 rating but edit content as needed to avoid the restricted rating. The NUDITY variable was added into the model in an effort to separate horror movie violence from movies with both horror movie violence and female frontal nudity. Many films in the horror movie genre focus on young males as a primary patron. The hypothesis put forth by the authors is that female nudity for a movie already earning the restricted rating might have extra appeal to the young male core audience. The empirical results reject this hypothesis as the NUDITY variable is positive but statistically insignificant in both model specifications.

The last variable in the model is BUDGET. The BUDGET variable is a positive and statistically significant determinant of opening weekend box office revenue for horror movies. Big budget movies with high profile movie stars, brand name directors, expensive special effects, and large advertising budgets have an obvious advantage drawing crowds at the box office. Some big budget movies in the research sample include Van Helsing ( $\$ 198$ million budget, $\$ 60.4$ million in opening weekend box office revenue), What Lies Beneath ( $\$ 115$ million budget, $\$ 38$ million in opening weekend box office revenue), and The Haunting ( $\$ 105$ million budget, $\$ 44$ million in opening weekend box office revenue).

\section{CONCLUSION}

The horror movie genre is a unique form of entertainment that tends to focus on scaring us with monsters, gore, the element of surprise, or fear of the unknown. The dark shadows and deliberate music that are often the hallmark of horror movies have helped the genre achieve box office success since the early years of the motion picture industry. This study examines the determinants of horror movie opening weekend box office revenue for the years 1978-2010. The most interesting result of the study is the observation that vampire and slasher movies are the most profitable theme and horror movies with comedic tendencies are the least profitable theme in the horror movie genre. Fictional characters have always driven the horror movie genre. The early years of the horror movies focused on characters like Dracula, Frankenstein, and The Wolfman. The modern star fictional characters with box office draw are slasher killers like Freddy, Jason, and Jigsaw or the teenage vampires like Edward from the Twilight series. The number of theatres featuring a movie during opening weekend release, and holiday releases, are revealed to have a significant impact on opening weekend box office revenue. One of the most influential determinants of opening weekend box office performance of horror movies is critical acclaim. Horror movies are one of the most harshly reviewed movie genres. The fact that the majority of horror movies receive poor critical reviews creates a box office opportunity for the relatively rare horror movies that receive critical acclaim. Movie sequels are shown to have a positive and statistically significant impact on opening weekend box office performance of horror movies. The built in audience associated with a sequel is worth approximately $\$ 4$ million in opening weekend box office revenue, holding other variables constant. Horror movies earning a restricted rating suffer a significant opening weekend box office penalty of $\$ 6$ million to $\$ 10$ million. Production budget is also identified as a significant determinant of domestic box office performance. Holding other variables constant, every extra dollar added to the budget of a movie immediately returns approximately 13 cents on the opening weekend. One avenue for future research extending the exploration of the horror movie genre profitability is to extend the research focus to the foreign box office or home and video on demand markets. A second avenue for future research is focusing on other specialty genres, which include comedy, science fiction, action, and sports movies. 


\section{AUTHOR INFORMATION}

Dr. Neil Terry is dean and professor of economics at West Texas A\&M University in Canyon, Texas. Dr. Terry earned a Ph.D. in economics from Texas Tech University.

Robert King is graduate student and research assistant in the College of Business at West Texas A\&M University in Canyon, Texas.

Robin Patterson is an instructor of business law at West Texas A\&M University in Canyon, Texas. Dr. Patterson earned a J.D. from the University of New Mexico.

\section{REFERENCES}

1. Anast, P. (1967). Differential movie appeals as correlates of attendance. Journalism Quarterly, 44, 86-90.

2. Austin, B. (1984). Portrait of an art film audience. Journal of Communication, 34 (winter), 74-87.

3. Chiou, L. (2008). The timing of movie releases: Evidence from the home video industry. International Journal of Industrial Organization, 26 (5), 1059-1073.

4. Cucco, M. (2009). The promise is great: the blockbuster and the Hollywood economy. Media Culture Society, 31, 215-230.

5. Dodds, J. \& M. Holbrook (1988). What's an oscar worth? An empirical estimation of the effect of nominations and awards on movie distribution and revenues. Current Research in Film: Audiences, Economics and the Law, 4, 72-88.

6. Einav, L. (2001). Seasonality and competition in time: An empirical analysis of release date decisions in the U.S. motion picture industry. Working Paper, Harvard University.

7. Einav, L. (2007). Seasonality in the U.S. motion picture industry. The RAND Journal of Economics, 38 (1), 127.

8. Eliashberg, J. \& S. Shugan (1997). Film critics: Influencers or predictors? Journal of Marketing, 61, 6878.

9. Faber, R. \& T. O'Guinn (1984). Effect of media advertising and other sources on movie selection. Journalism Quarterly, 61 (summer), 371-377.

10. King, T. (2007). Does film criticism affect box office earnings? Evidence from movies released in the U.S. in 2003. Journal of Cultural Economics, 31, 171-186.

11. Lee, F. L. (2009). Cultural discount of cinematic achievement: The Academy Awards and U.S. movies' East Asian box office. Journal of Cultural Economics, 33 (4), 239-263.

12. Levene, C. (1992). Marketing art-films to college students. Working Paper, The Wharton School, University of Pennsylvania.

13. Litman, B. (1983). Predicting success of theatrical movies: An empirical study. Journal of Popular Culture, 16 (spring), 159-175.

14. Litman, B. \& H. Ahn (1998). Predicting financial success of motion pictures. In B.R. Litman, The Motion Picture Mega-Industry, Allyn \& Bacon Publishing, Inc.: Boston, MA.

15. Litman, B. \& A. Kohl (1989). Predicting financial success of motion pictures: The 80's experience. The Journal of Media Economics, 2 (1), 35-50.

16. Liu, Y. (2006). Word of mouth for movies: Its dynamics and impact on box office revenue. Journal of Marketing, 70 (3), 74-89.

17. Neelamegham, R. \& P. Chinatagunta (1999). A Bayesian model to forecast new product Performance in domestic and international markets. Marketing Science, 18 (2), 115-136.

18. Nelson, R., M. Donihue, D. Waldman \& C. Wheaton (2001). What's an Oscar worth? Economic Inquiry, $39(1), 1-16$.

19. Radas, S. \& S. Shugan (1998). Seasonal marketing and timing introductions. Journal of Marketing Research, 35 (3), 296-315.

20. Ravid, A. (1999). Information, blockbusters, and stars: A study of the film industry. Journal of Business, 72 (4), 463-492. 
21. Reinstein, D. \& C. Snyder (2000). The influence of expert reviews on consumer demand for experience goods: A case study of movie critics. Working Paper, University of California-Berkeley and George Washington University.

22. Robertson, P. (2001). Film facts. New York, Billboard Books.

23. Rosen, S. (1981). The economics of superstars. American Economic Review, 71 (5), 845-858.

24. Sawhney, M. \& J. Eliashberg (1996). A parsimonious model for forecasting gross box office revenues of motion pictures. Marketing Science, 15 (2), 113-131.

25. Simonoff, J. \& I. Sparrow (2000). Predicting movie grosses: Winners and losers, blockbusters and sleepers. Chance Magazine, 13 (3), 15-24.

26. Smith, S. \& V. Smith (1986). Successful movies: A preliminary empirical analysis. Applied Economics, 18, 501-507.

27. Sochay, S. (1994). Predicting the performance of motion pictures. The Journal of Media Economics, 7 (4), $1-20$.

28. Terry, N., M. Butler \& D. De'Armond (2004). The economic impact of movie critics on box office performance. Academy of Marketing Studies Journal, 8 (1), page 61-73.

29. Terry, N. \& D. De'Armond (2008). The determinants of movie rental revenue earnings. Academy of Marketing Studies Journal, 12 (2), page 35-47.

30. Terry, N., R. King \& J. Walker (2010). Determinants of box office revenue for horror movies. Journal of Global Business Management, 6 (2), 230-239.

31. Vogel, H. (1998) Entertainment industry economics: A guide for financial analysis. Cambridge: Cambridge University Press.

32. Wallace, T, A. Seigerman \& M. Holbrook (1993). The role of actors and actresses in the success of films: How much is a movie star worth? Journal of Cultural Economics, 17 (1), 1-27.

33. Weiman, G. (1991). The influentials: Back to the concept of opinion leaders. Public Opinion Quarterly, $55,267-279$.

34. Wyatt, R. \& D. Badger (1984). How reviews affect interest in and evaluation of films. Journalism Quarterly, 61 (winter), 874-878.

35. Wyatt, R. \& D. Badger (1987). To toast, pan or waffle: How film reviews affect reader interest and credibility perception," Newspaper Research Journal, 8 (summer), 19-30.

36. Wyatt, R. \& D. Badger (1990). Effects of information and evaluation in film criticism. Journalism Quarterly, 67 (summer), 359-368. 
NOTES 